\title{
A Rationale Strategy to Tune the Optical \\ Properties of Gold Catenane Nanoclusters by \\ Doping with Silver Atoms
}

Srestha Basu, ${ }^{\dagger}$ Martina Perić Bakulić, ${ }^{\perp}$ Hussein Fakhouri, ${ }^{\perp}++$ Isabelle Russier-

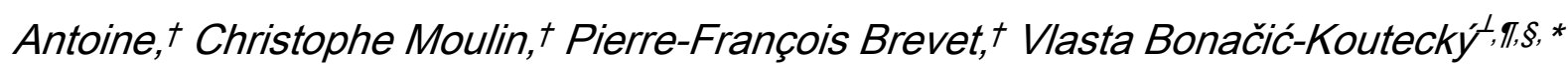

and Rodolphe Antoinet, *

† Univ Lyon, Université Claude Bernard Lyon 1, CNRS, Institut Lumière Matière, F-

69622, LYON, France

${ }^{\perp}$ Center of Excellence for Science and Technology-Integration of Mediterranean

Region (STIM), Faculty of Science, University of Split, Ruđera Boškovića 33, 21000

Split, Croatia

IInterdisciplinary Center for Advanced Science and Technology (ICAST) at University

of Split, Meštrovićevo šetalište 45, 21000 Split, Croatia 
$\S$ Department of Chemistry, Humboldt Universitatzu Berlin, Brook-Taylor-Strasse 2,

12489 Berlin, Germany

\section{Supporting Information}




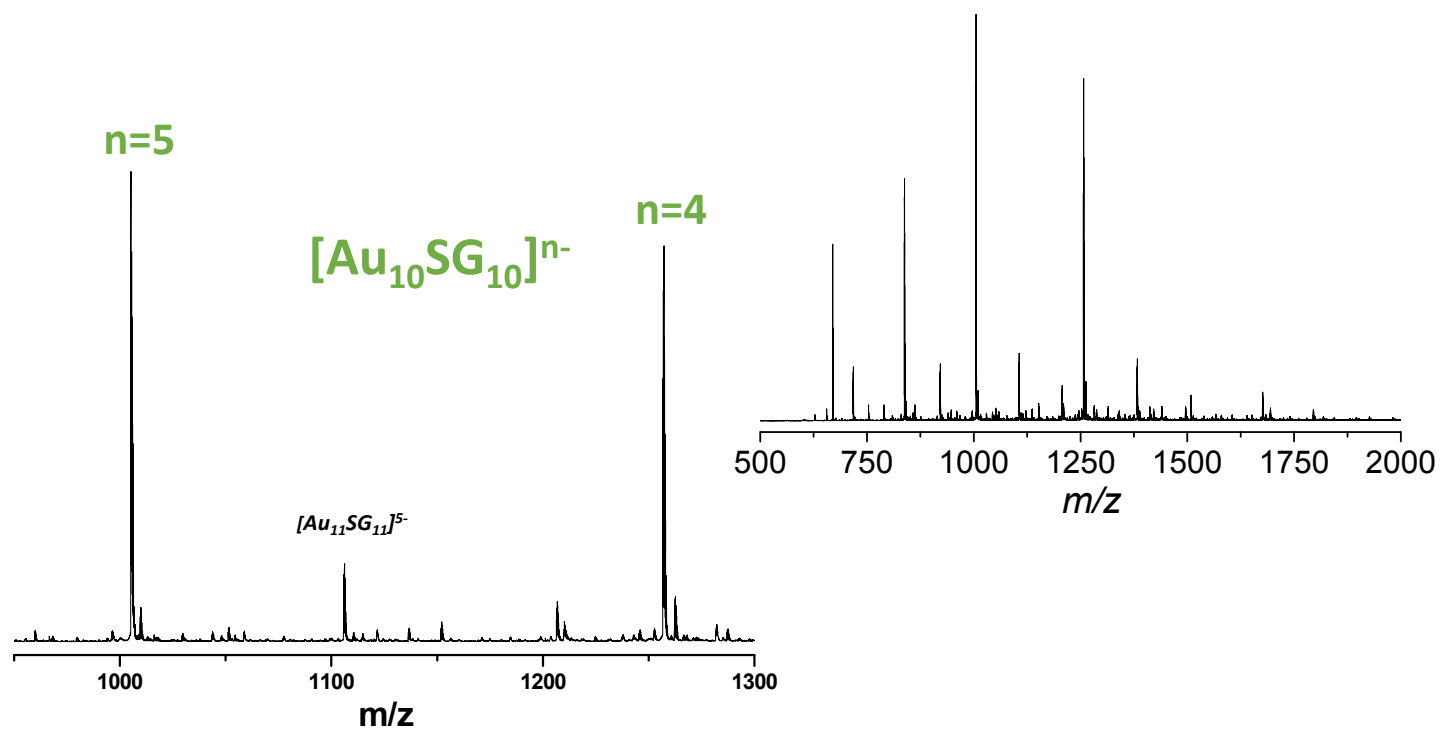

Figure S1. Experimentally observed ESI-MS spectrum of $\mathrm{Au}_{10} \mathrm{SG}_{10}$. Inset : ESI-MS spectrum with expanded $\mathrm{X}$-axis. 
a)
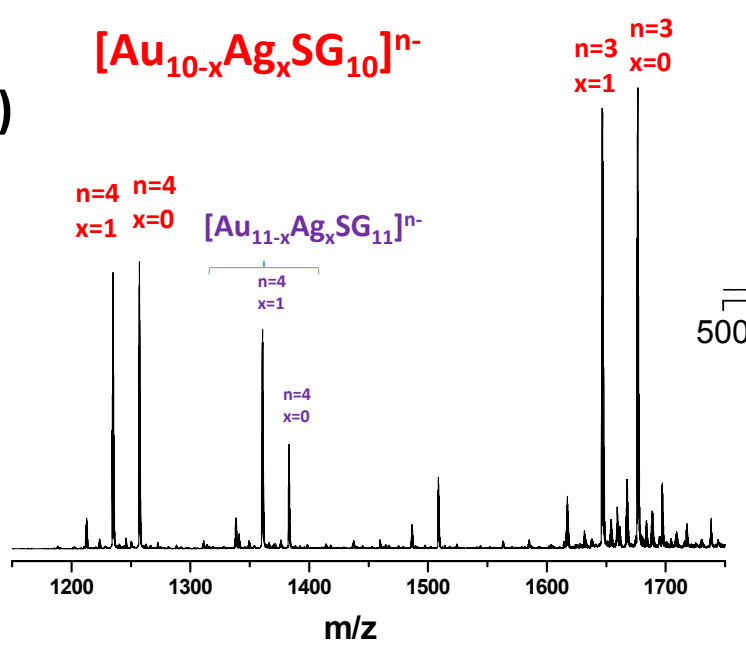

500750100012501500175020002250

$m / z$

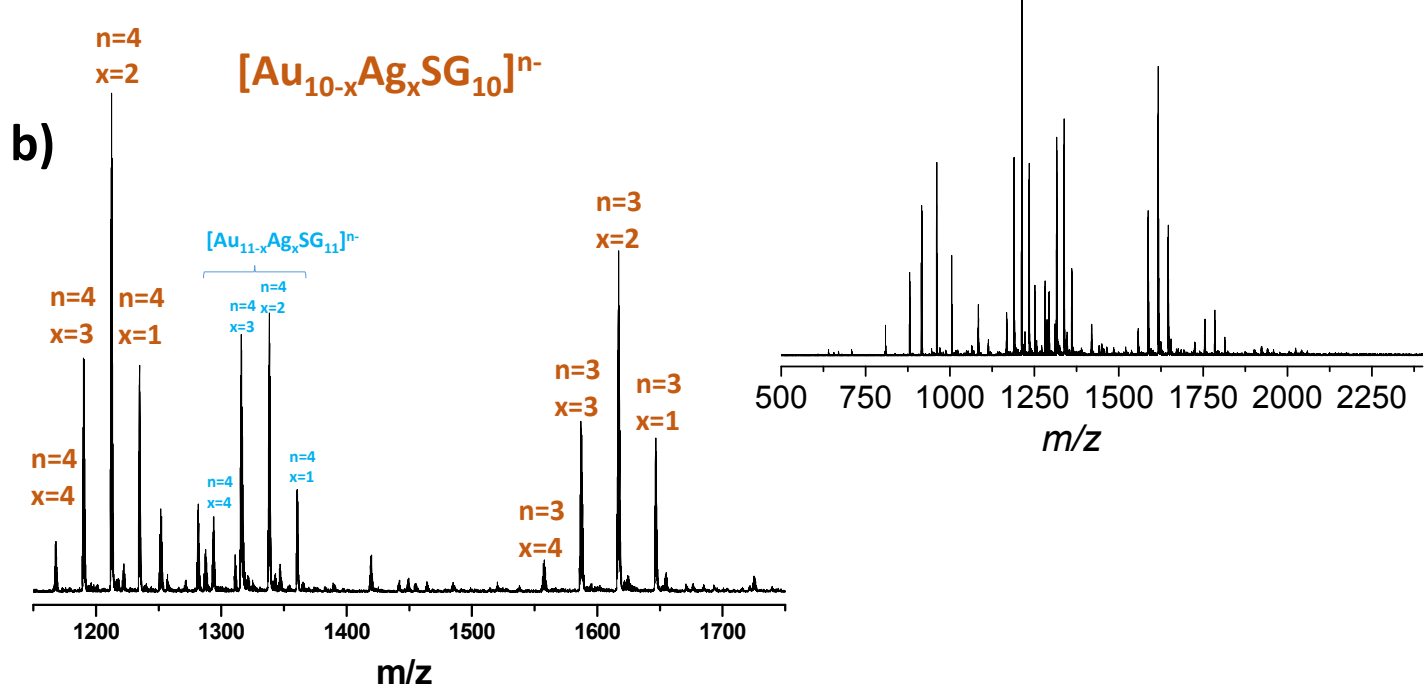

Figure S2. Experimentally observed ESI-MS spectrum of a) $A u_{10-x} A g_{x} S G_{10}$ with $x=0-2$ and b) $A u_{10-x} A g_{x} S G_{10}$ with $x=1$-4. Insets : ESI-MS spectrum with expanded X-axis. 


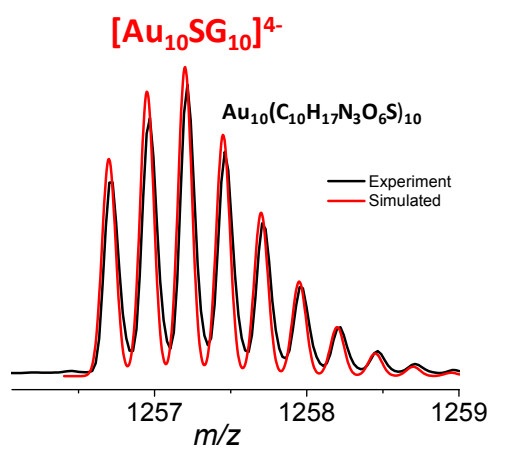

$\left[\mathrm{Au}_{7} \mathrm{Ag}_{3} \mathrm{SG}_{10}\right]^{4-}$

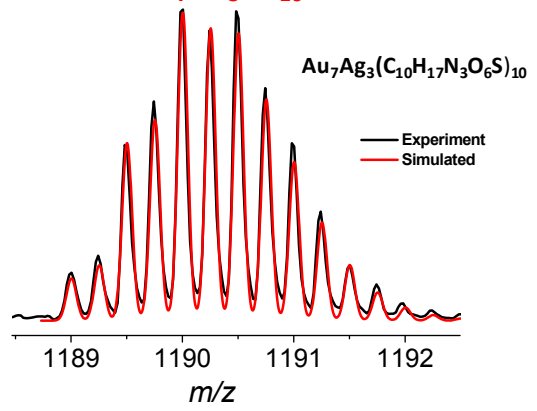

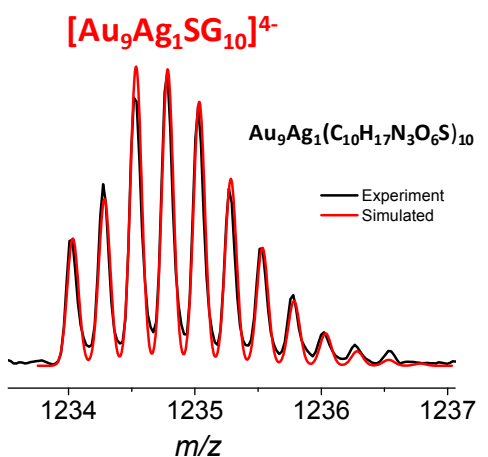

$\left[\mathrm{Au}_{6} \mathrm{Ag}_{4} \mathrm{SG}_{10}\right]^{4-}$

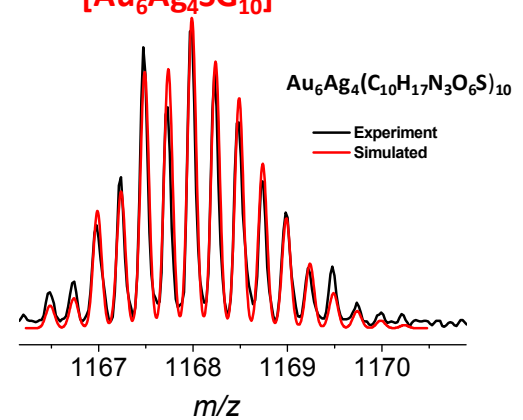

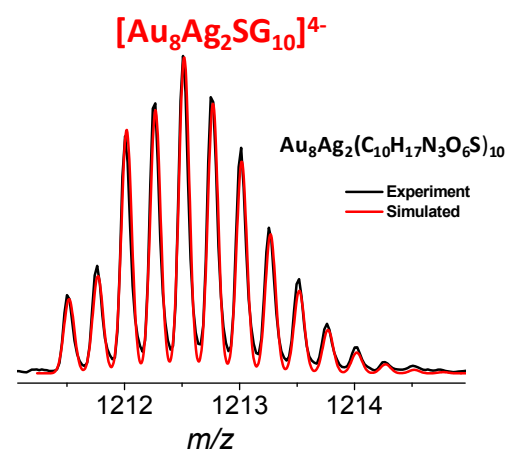

Figure S3. Experimentally observed and simulated ESI-MS isotopic patterns of different $A u_{10}$ and silver-doped nanoclusters. 


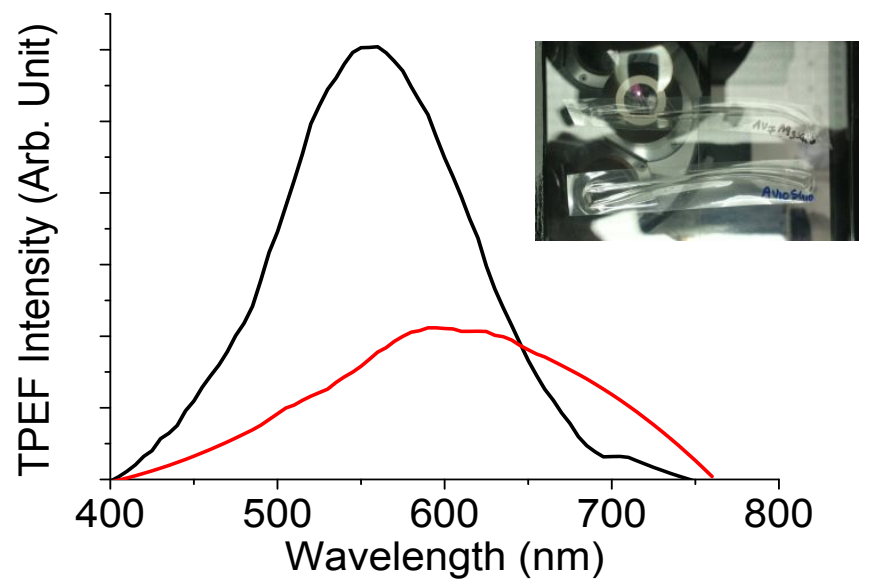

Figure S4. Two-photon excited fluorescence spectra at excitation wavelength $780 \mathrm{~nm}$ of $\mathrm{Au}_{10} \mathrm{SG}_{10}$ (black line) compared to silver doped $\mathrm{Au}_{10-\mathrm{x}} \mathrm{Ag}_{\mathrm{x}} \mathrm{SG}_{10}$ with $\mathrm{x}=1-4$ in gels (red line, with the same NCs concentration $\sim 750 \mu \mathrm{M}$ ). Insets : photos of gels of NCs used for TPEF measurements. TPEF measurements were performed on nanoclusters-containing gels with a customized confocal microscope. 


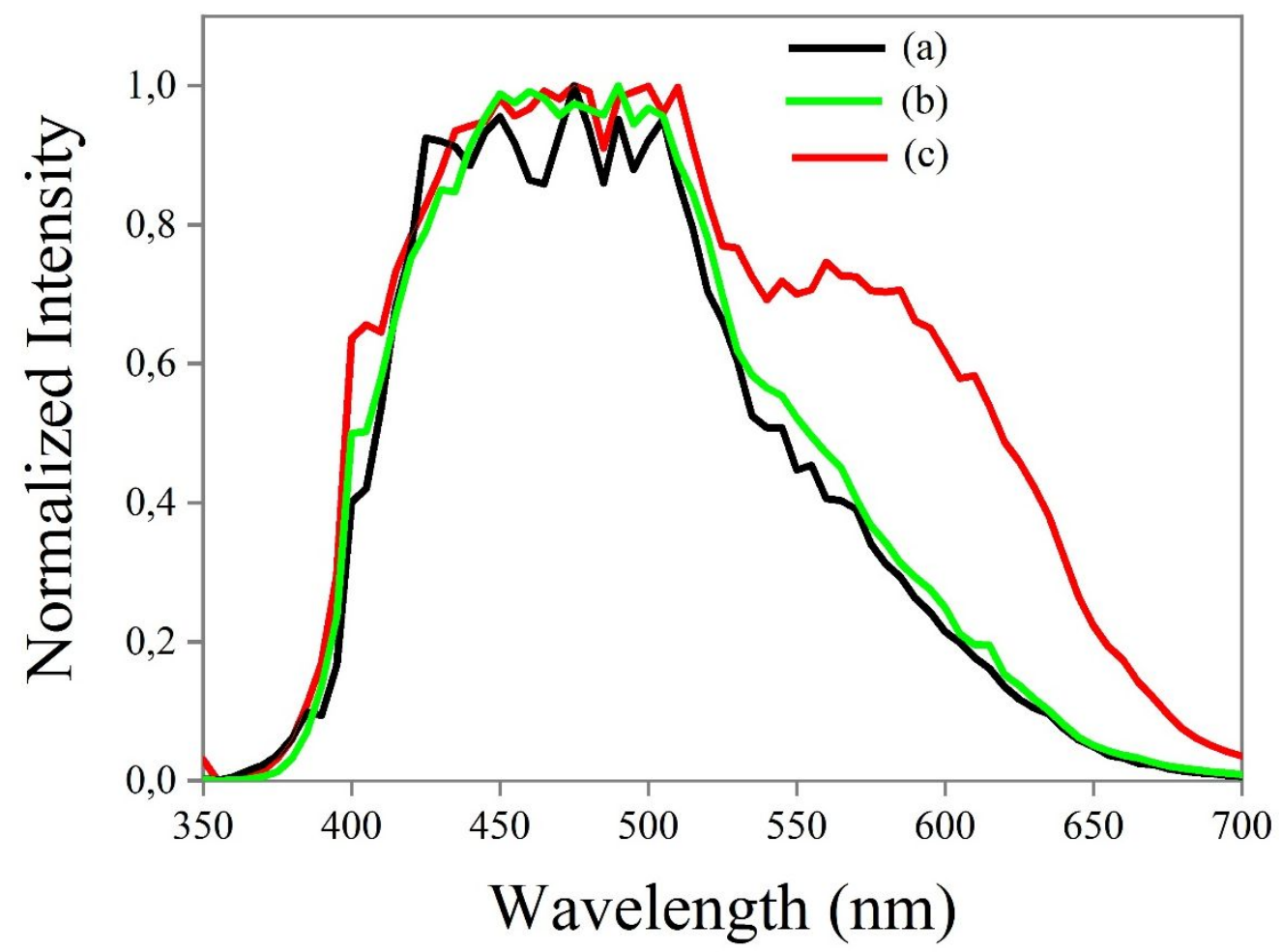

Figure S5: TPEF spectra of (a) $\mathrm{Au}_{10} \mathrm{SG}_{10}$, (b) $\mathrm{Au}_{10-\mathrm{X}} \mathrm{Ag}_{\mathrm{X}} \mathrm{SG}_{10} ; \mathrm{x}=0-2$ and (c) $\mathrm{Au}_{10-\mathrm{X}} \mathrm{Ag}_{\mathrm{X}} \mathrm{SG}_{10}$ $(x=1-4)$. Spectra were recorded in aqueous solution and the TPEF signal was detected with the model H11890-210 photomultiplier tube (Hamamatsu). 

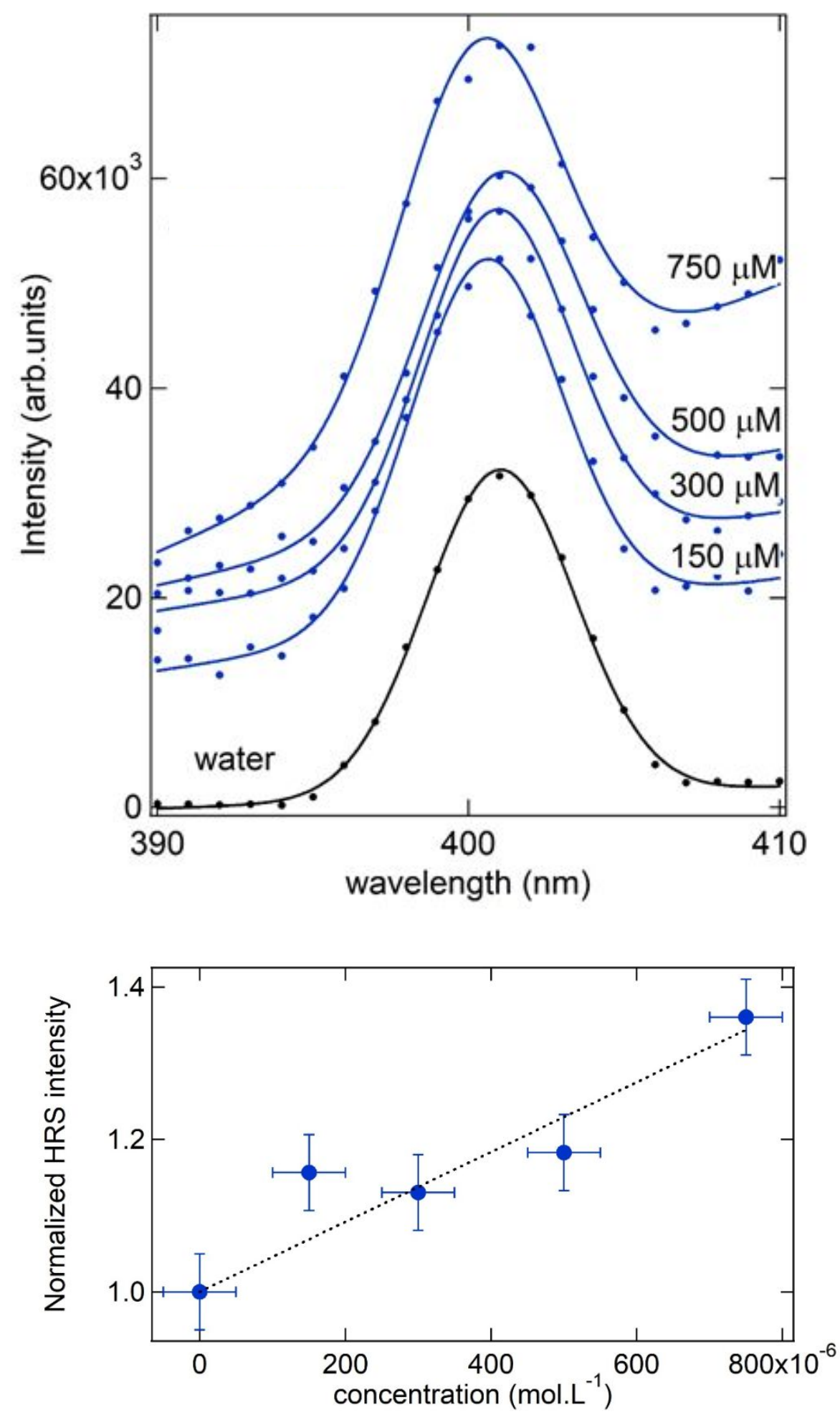

Figure S6. HRS line intensity as a function of varying concentration of $\mathrm{Au}_{10-\mathrm{x}} \mathrm{Ag}_{\mathrm{x}} \mathrm{SG}_{10}$ with $\mathrm{x}=1-4$. Plot of variation of normalized HRS intensity as function of concentration of $\mathrm{Au}_{10-\mathrm{x}} \mathrm{Ag}_{\mathrm{x}} \mathrm{SG}_{10}$ with $\mathrm{x}=1-4$. 


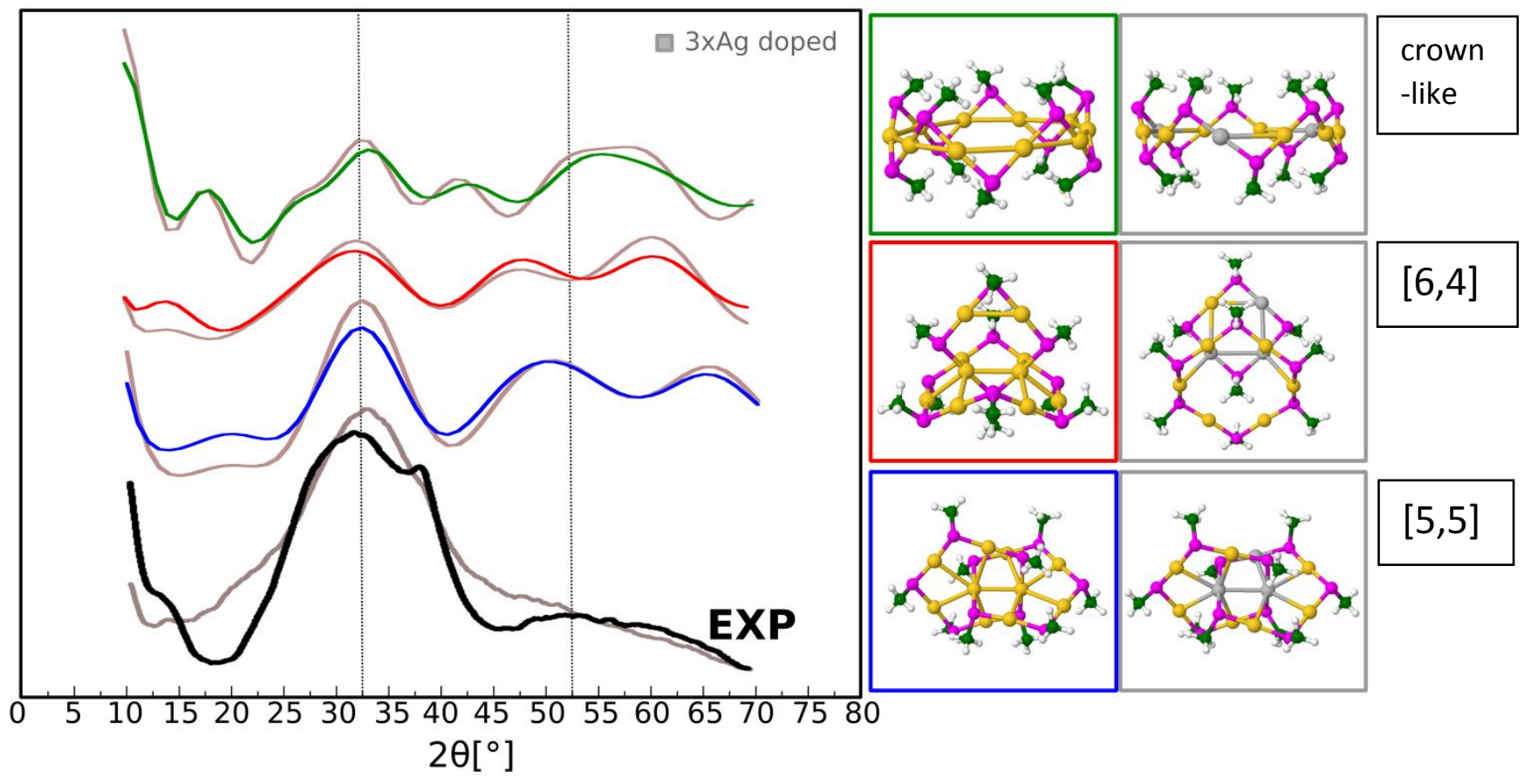

Figure S7. Experimentally obtained XRD patterns of $\mathrm{Au}_{10}(\mathrm{SG})_{10}$ (black), $\operatorname{Au}_{7} \mathrm{Ag}_{3}(\mathrm{SG})_{10}$ (grey) and calculated patterns for different DFT isomeric structures of Au10 pure and $\mathrm{Au}_{7} \mathrm{Ag}_{3}(\mathrm{SG})_{10}$ doped ligated clusters $\left(\mathrm{L}=\mathrm{SCH}_{3}\right)$ (blue: catenane structure [5,5]; red: structure containing two intercalated rings of different size [6,4]; green: crown-like structure, grey: $\mathrm{Ag}$ doped isomers respectively). 

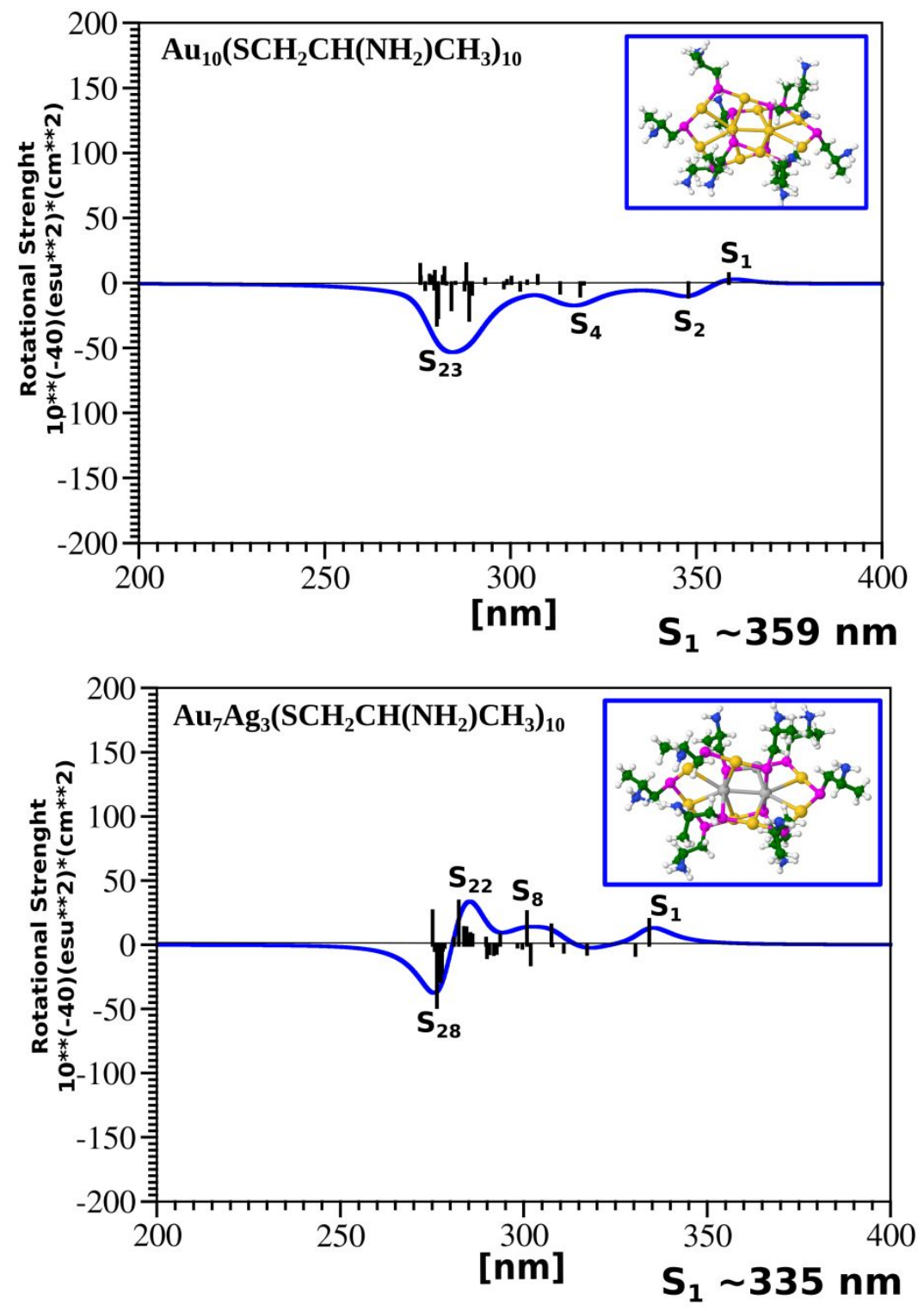

Figure S8. DFT calculated CD spectra of the pure gold ligated cluster and silver-doped one $(\mathrm{L}=(-\mathrm{SCH} 2 \mathrm{CH}(\mathrm{NH} 2) \mathrm{CH} 3)$.$) .$

First Hyperpolarizability $\left(\mathrm{x} 10^{-30} \mathrm{esu}\right)$

\begin{tabular}{|c|c|c|}
\hline$\lambda[\mathrm{nm}]$ & $\mathrm{Au}_{10}\left(\mathrm{SCH}_{2} \mathrm{CH}\left(\mathrm{NH}_{2}\right) \mathrm{CH}_{3}\right)_{10}$ & $\mathrm{Au}_{7} \mathrm{Ag}_{3}\left(\mathrm{SCH}_{2} \mathrm{CH}\left(\mathrm{NH}_{2}\right) \mathrm{CH}_{3}\right)_{10}$ \\
\hline $600 \mathrm{~nm}$ & 2250.70 & 71.56 \\
\hline $700 \mathrm{~nm}$ & 57.78 & 9.57 \\
\hline $800 \mathrm{~nm}$ & 2.74 & 7.58 \\
\hline
\end{tabular}

Table S 1 DFT calculated first hyperpolarizabilities for pure gold and silver doped ligated clusters at different wavelengths. 